\title{
Biohazardous Substance
}

National Cancer Institute

\section{Source}

National Cancer Institute. Biohazardous Substance. NCI Thesaurus. Code C1281.

A biological or chemical substance that exerts toxic or pathologic effects on living entities. 